\title{
Improving the Assessment of Potential and Actual Impacts of Climate Change and Extreme Events Through a Parallel Modeling of Climatic and Societal Changes at Different Scales
}

\author{
Stefan Greiving*, Sophie Arens, Dennis Becker, \\ Mark Fleischhauer and Florian Hurth \\ Institute of Spatial Planning (IRPUD), \\ Technische Universität Dortmund, \\ D-44221 Dortmund, Germany
}

Published 12 April 2018

\begin{abstract}
Any adaptation activity needs a reliable evidence basis for the climate itself as well as for the exposition and sensitivity of the social, economic or ecological system and its elements. This requires an assessment of recent climate impacts as well as potential future climate change impacts in order to select tailor-made adaptation measures. For a methodologically coherent assessment, the Intergovernmental Panel on Climate Change (IPCC) had introduced the requirement of a parallel modeling approach which means that demographic and socioeconomic changes are projected in parallel to the changes of the climatic system. This paper discusses a conceptual framework of a parallel modeling approach and presents its application in four case studies of climate change impact assessments in Germany, covering the national, regional and local scale. The results from the different applications prove the hypothesis that the change in sensitivity (i.e., demographic change, economic change and change in land-use patterns) often determines the magnitude of climate- and weatherrelated impacts in the near future significantly. The case studies, however, also show that adaptation processes have to be organized in a collaborative way, which takes the knowledge, and also the concerns of the addressees into full account. A broad mandate from all social groups is especially needed when political decisions are based on uncertain knowledge - which is the case whenever climate change impacts are assessed.
\end{abstract}

Keywords: Climate change; societal change; extreme events; modelling; impact assessment; spatial planning.

*Corresponding author's email: stefan.greiving@tu-dortmund.de

This is an Open Access article published by World Scientific Publishing Company. It is distributed under the terms of the Creative Commons Attribution 4.0 (CC-BY) License. Further distribution of this work is permitted, provided the original work is properly cited. 


\section{Introduction}

The purpose of this paper is the discussion of a parallel modeling approach as a conceptual framework for conducting climate impact assessments on different spatial scales. The approach, which is characterized by analyzing and processing present and future climate change as well as sensitivity data, is presented in Section 2. Climate impact assessments serve as an evidence basis for adaptation to climate change, e.g., by mainstreaming adaptation activities in spatial development strategies. The paper presents case studies where this conceptual framework was applied on various spatial scales (Section 3).

The paper follows the hypothesis that parallel modeling is indispensably needed for any adaptation action because the change of sensitivity-related elements in the socio-ecologic system may determine the extent of climate- and weather-related impacts in the future significantly.

The climate has always been changing as a result of changes in various factors such as solar activity, the earth's orbit around the sun, the atmospheric composition and large volcanic activities (EEA 2012: 49). The extent and impact of human influence on today's and the future's climate system has become evident as recent anthropogenic emissions of greenhouse gases have reached the highest level in human history. Consequently, recent climate changes have already had widespread impacts on human and natural systems and will have even more severe impacts in future (Intergovernmental Panel on Climate Change [IPCC] 2014: 40).

The extent and territorial patterns of these impacts cannot be precisely predicted due to uncertainty with regard to further greenhouse gas emissions, which depend on demographic, socioeconomic and technological development. But also the implementation of global, national and local mitigation policies in the future is uncertain (EEA 2012: 53f). Moreover, these developments influence the sensitivity to changes in the climatic system on the regional and local scale and also the ability to adapt to these changes. Thus, there is a need for "better informed decision-making” in addressing these impacts amidst a changing and uncertain environment (EC 2013).

In general, "uncertainties about future climate change are smaller for changes in temperature than for precipitation and other climate variables, for changes at global and continental scales than at regional scale, and for changes in mean climate than for extreme events" (EEA 2012: 54). For example, the occurrence of current 100 -year return floods are projected to increase in continental Europe, but to decrease in some parts of Northern and Southern Europe by 2100 (Rojas et al. 2012). However, these trends are rather uncertain (EEA 2016: 39). 
There are connections between climate change and hydro-meteorological extreme events and the combined impacts of projected climate change and socioeconomic developments (e.g., in floodplains) that can lead to higher damage costs (EEA 2012). Disaster risk management can therefore contribute to climate change adaptation (Costa and Kropp 2012; Field et al. 2012). However, the scope of adaptation goes beyond dealing with extreme events and addresses also creeping changes in temperature and precipitation and related impacts on the society and the environment. Moreover, standard applications of disaster risk assessment are primarily concerned with short-term (rapid-onset) natural hazards, and assume that hazards are known and current vulnerabilities are static (EEA 2017), disregarding that vulnerability assessments to climate change need to be future-oriented.

Territorially differentiated impacts of climate change - provided by a climate impact analysis - may significantly improve the spatial dimension of adaptation policy by stressing the spatial differentiation of impacts. Spatial development is regarded to be responsible for and capable of reducing regional impacts of climate change and developing climate adaptation capacities. Climate change impacts occur in specific places and can give rise to conflicts with land use and regional development, requiring a need to find territorially relevant answers to these challenges (Greiving and Fleischhauer 2012). For example, the future of European Cohesion Policy should be discussed against the background of regional imbalances and the estimated inequalities of climate change impacts (Greiving et al. 2013).

At the national level, most of the 21 existing adaptation strategies in European Union (EU) Member States refer not only to the various affected sectors such as agriculture, water, human health and the environment (as the most commonly mentioned sectors), but also to territorial development in general and spatial planning in particular (EEA 2014; Greiving and Fleischhauer 2012). At local level, attention is mainly drawn on coping with urban heat and pluvial flooding, with urban development agencies as the key actors (Reckien et al. 2014).

The collaborative and transformative character of adaptation is crucial. Transformative adaptation that complements coping and incremental adaptation is a new challenge for governance as it may imply fundamental shifts in power and representation of interests and values. The IPCC argues that "adaptive responses to a changing climate require actions that range from incremental changes to more fundamental, transformational changes" (IPCC 2014: 76). In some locations, such as coastal zones threatened by sea level rise and storm surges, river valleys prone to floods or mountain valleys affected by alpine hazards, "responses could also require transformational changes such as managed retreat” (IPCC 2014: 97), which could be financially supported by EU structural funds. 
A particular need that must be met for adaptation at all spatial scales is the establishment of a broad stakeholder involvement (Knieling and Filho 2013). That is indispensably needed for the acceptability, but also applicability of adaptation measures that are widely targeted to civil society (such as adaptation of the building stock or agricultural activities). Moreover, political decisions based on uncertain knowledge need a broad mandate from all social groups (Fleischhauer et al. 2012; Greiving and Fleischhauer 2012; Walker et al. 2014). The directly affected stakeholders should be involved in these efforts from the early beginning of the planning process until the implementation of the adaptation measures. This is particularly relevant for regional and local adaptation efforts that should be mainstreamed in regional and urban development (EEA 2012; Kern and Bulkeley 2009).

Regional and urban development agencies have the potential to play an important role in climate change adaptation due to its integrative, cross-sectoral character. As climate change impacts occur in specific places and might cause conflicts with land use and regional development there is a need to find territorially relevant answers to this challenge. At the same time, spatial planning tools offer a variety of approaches to reduce the negative impacts of climate change leading to the question what the role of spatial planning is in fact (Greiving and Fleischhauer 2012). Climate change adaptation calls for a crosssectoral approach because of the variety of impacts on different sectors and the interdependencies between impacts and response strategies. Also Mickwitz et al. (2009) argued for a prominent role for comprehensive spatial planning in this regard. Nonadapted urban development with economic growth and urbanization of landscapes that is exposed to climate hazards like floods or droughts may increase the exposure of human settlements and infrastructures and reduce the resilience of natural systems. Adaptation to climate change and sustainable development are intertwined as adaptive capacity building contributes to the wellbeing of both social and ecological systems globally. According to the IPCC AR5, "Effective implementation of adaptation policies depends on cooperation at all scales and can be enhanced through integrated responses that link adaptation with other societal objectives" (IPCC 2014: 94). There are also other socioeconomic trends (such as demographic trends and land-use changes) that are influenced by various impacts of climate change and vice versa, and that furthermore determine the given capacities to adapt. That is why regional and urban development agencies are asked to base judgments on adaptation on a parallel modeling approach of climatic and socioeconomic trends as explained in more detail in Section 2. 


\section{The Parallel Modeling Approach}

Any kind of adaptation activities need to be evidence based (EC 2013), regardless of the fact that vulnerability assessments for climate change are characterized by uncertainty (Webb 2017). The same is true for disaster risks as propagated by the Sendai Framework for Disaster Risk Assessment where Priority 1 is titled "Understanding disaster risk” (UN 2015).

There is always an enormous bandwidth of potential future climatic and socioeconomic conditions. Basically, in current vulnerability studies, the system, such as it is right now, is pitted against future climate change as if this change was to happen more or less entirely tomorrow (see European Environment Agency 2017 for an overview).

The uncertainties about future climate change impacts require a so-called parallel modelling approach. ${ }^{1}$ This means that demographic and socioeconomic changes are projected in parallel to the changes of the climatic system in order to assess the future impact of climate change on future society. This is not only relevant on the global level as a basis for emission scenarios, but also on the regional and local levels in order to derive tailor-made adaptation strategies (Birkmann and Mechler 2015; van Ruijven et al. 2014). In this context, the assessment should be based on a scenario combination of climatic scenarios derived from an ensemble of climatic models and socioeconomic scenarios in order to reflect the bandwidth of potential future conditions (Greiving et al. 2015, see also Figure 1).

The recent amendment of the environmental impact assessment (EIA) directive (2014/52/EU) underlines the need for a parallel modeling approach by stating: "Climate change will continue to cause damage to the environment and compromise economic development. In this regard, it is appropriate to assess the impact of projects on climate (for example greenhouse gas emissions) and their vulnerability to climate change” (EC 2014). Consequently, a so-called "evolving baseline trend" (of both climate and society) has to be taken into account when assessing the effects of a plan or project on the environment (EEA 2013). A similar reference is

\footnotetext{
${ }^{1}$ The "parallel modelling approach" was introduced in IPCC AR5 (IPCC 2014) with the parallel approach of the Representative Concentration Pathways. As succinctly described by van Vuuren et al. (2011) "Socio-economic and emission scenarios are used in parallel to provide plausible descriptions of how the future may evolve with respect to a range of variables including socioeconomic change, technological change, energy and land use, and emissions of greenhouse gases and air pollutants. They are used as input for climate model runs” (van Vuuren et al. 2011: 6). This (global) parallel modelling approach was further elaborated with stress placed on local and regional level (and land use at these levels) as a basis for assessment of possible local and regional climate impacts by van Ruijven et al. (2014) and Greiving et al. (2015).
} 
missing in the Strategic Environmental Directive (EC 2001), although the Directorate-General (DG) Environment argues for an inclusion of climate change (EC DG Environment 2013).

The change of the sensitivity (i.e., demographic change, economic change and change in land-use patterns) may determine - at least for rapidly growing or shrinking urban environments - the extent of climate- and weather-related impacts in the near future more significantly than the changing climate (temperature and precipitation mainly) itself. Due to this fact, for each time slice (present and future), a potential impact needs to be determined using either only recent monitoring data or only projections (for both, changes in the climate and the socioeconomic changes are taken into account) (Greiving et al. 2015). In doing so, the dynamics of climate change impacts can be determined.

Adaptive capacity is blended out from the assessment framework. That is particularly relevant because adaptive capacity by definition only relates to the future, i.e., to the possibility of implementing additional adaptation measures. The climate impact assessment approach presented here aims at creating a sound evidence basis for decisions on adaptation to climate change. Taking potential adaptation measures into account already during the assessment phase would definitely deteriorate the awareness and willingness of decision-makers to give priority to adaption instead of conflicting social or economic interests.

This concept of a progression of future change in climate impacts using the parallel modeling approach via time slices is visualized by Figure 1 and can be applied at various spatial levels.

\section{Reference period Future}

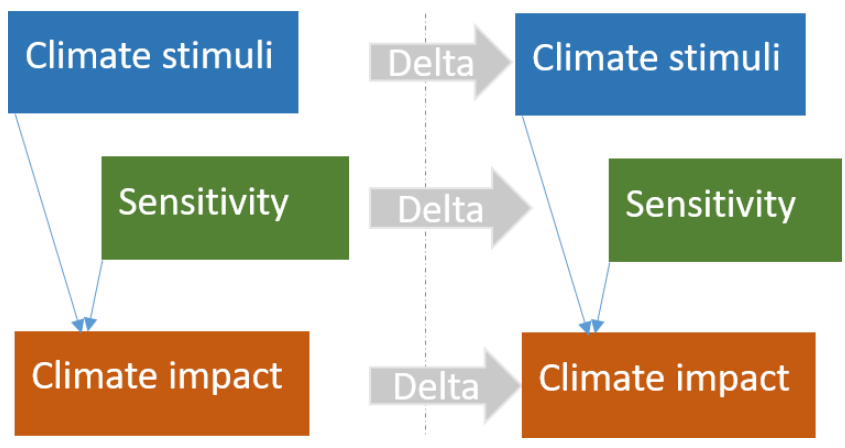

Figure 1. Time Slice Progression of Change in Future Impact Using a Parallel Modeling Approach Source: Own figure, based on Greiving et al. (2015: 315). 
The current status of a system is assessed on basis of climate data from a reference period (e.g., 1971-2000) and the current status of the environment (census data, land-use data). Depending on the available data base, the potential future status could be assessed for different time slices in the future, e.g.,

- The near future (time slice 2020-2050 for climate modeling data and for sociodemographic data) for which fine-grained socioeconomic data on demography and land-use changes are available,

- And a more remote future (2071-2100) in order to underline the seriousness of a further change in the climatic system. However, for the remote future, there is no reliable data available that would allow a quantitative projection of long-lasting socioeconomic trends - at least not at the local level. This requires more narrative statements based on experts' judgments.

A central question within the parallel modeling approach is how to address the uncertainty of future developments. In the approach presented here, the inherent uncertainty of climatic models is taken into account by using an ensemble which considers several global and regional models, as well as socioeconomic emission scenarios. Two ensemble members are used in parallel for each climatic stimulus (e.g., the 15th and 85th percentiles of all ensemble members). The uncertainty related to future socioeconomic conditions is taken into consideration by using different sensitivity scenarios (represented by the key variables changes in demography and land-use).

One possible solution is to treat sensitivity data similarly to climate change data. This means, in case of population data, to pick different population scenarios and build an ensemble of these and subsequently build percentiles (e.g., the 15th and 85th). However, the specific availability of different sensitivity scenarios has to be checked case-by-case. This method seems to be appropriate in case of a high uncertainty. In contrast, there might be cases where the specific development of the future sensitivity can be quite certain. If so, it may be applicable to include only one (realistic) sensitivity scenario for representing the future (e.g., if the sensitivity remains stable or the development is well-known). However, a key component of this approach is to base decisions on scenario combinations of climate change and changes in the sensitivity instead of just a change of the climatic system. That is also why Figure 2 shows a bandwidth of potential future conditions that is fed by both trends.

Nevertheless, normative questions remain: On which scenario combination should an adaptation strategy and subsequently the adaptation measures be based? A combination of rapid land-use change under extreme climate change or a more moderate one? The role of science in this context is problematic because science 
cannot give a proof of vulnerability in view of given uncertainty. Science in this context is inconclusive (van Asselt 2005). Hereby, justification of actions and consensus about thresholds for acceptable risks and response actions becomes more important (Fleischhauer et al. 2012; Walker et al. 2014).

Figure 2 illustrates the problem of decision-making under deep uncertainty.

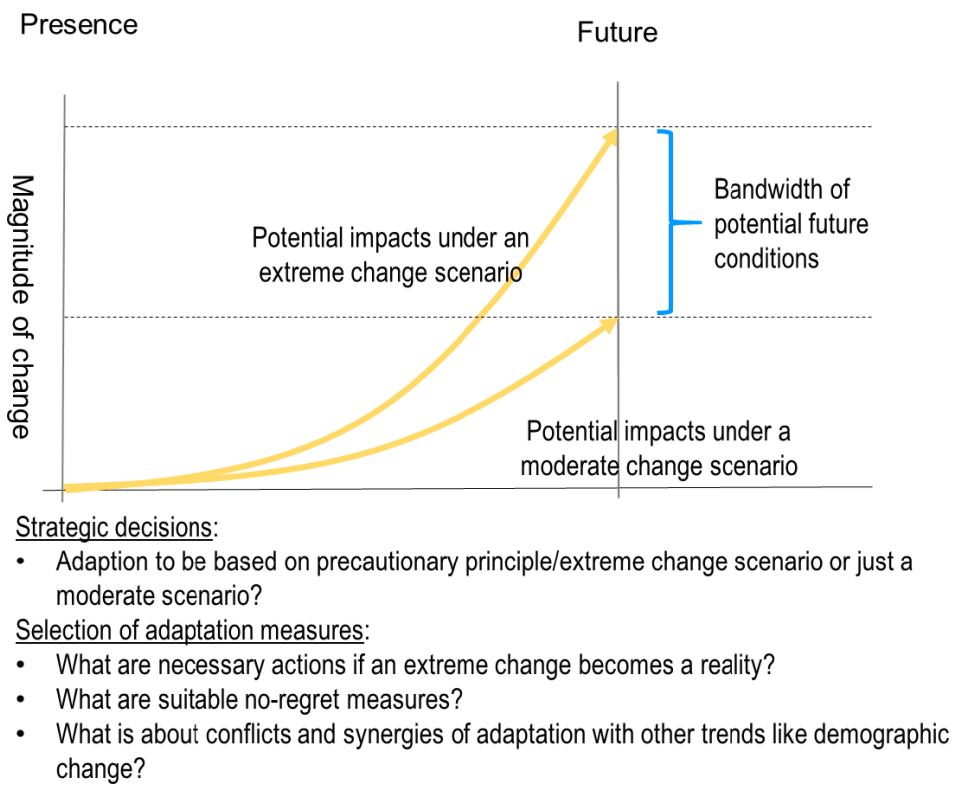

Evidence basis

Figure 2. Decision-Making under Deep Uncertainty

Source: Author.

\section{Application of the Parallel Modeling Approach on Different Spatial Levels}

In the following section, results from various applications of the aforementioned conceptual framework will be presented and discussed. A particular focus lies on approaches for modeling socioeconomic changes that are tailor-made to the respective spatial level of analysis. This requires different case studies that address the specific requirements of national, regional and local assessments in regard to methods, data and addressees/users of the results. Two local case studies were chosen in order to enlighten different elements of the assessment in greater detail: While the case study of the City of Hagen focuses on demographic changes, the case study of the City of Bonn points at reasonable alternatives of land-use changes. Table 1 gives an overview about the characteristics of the various case studies. 


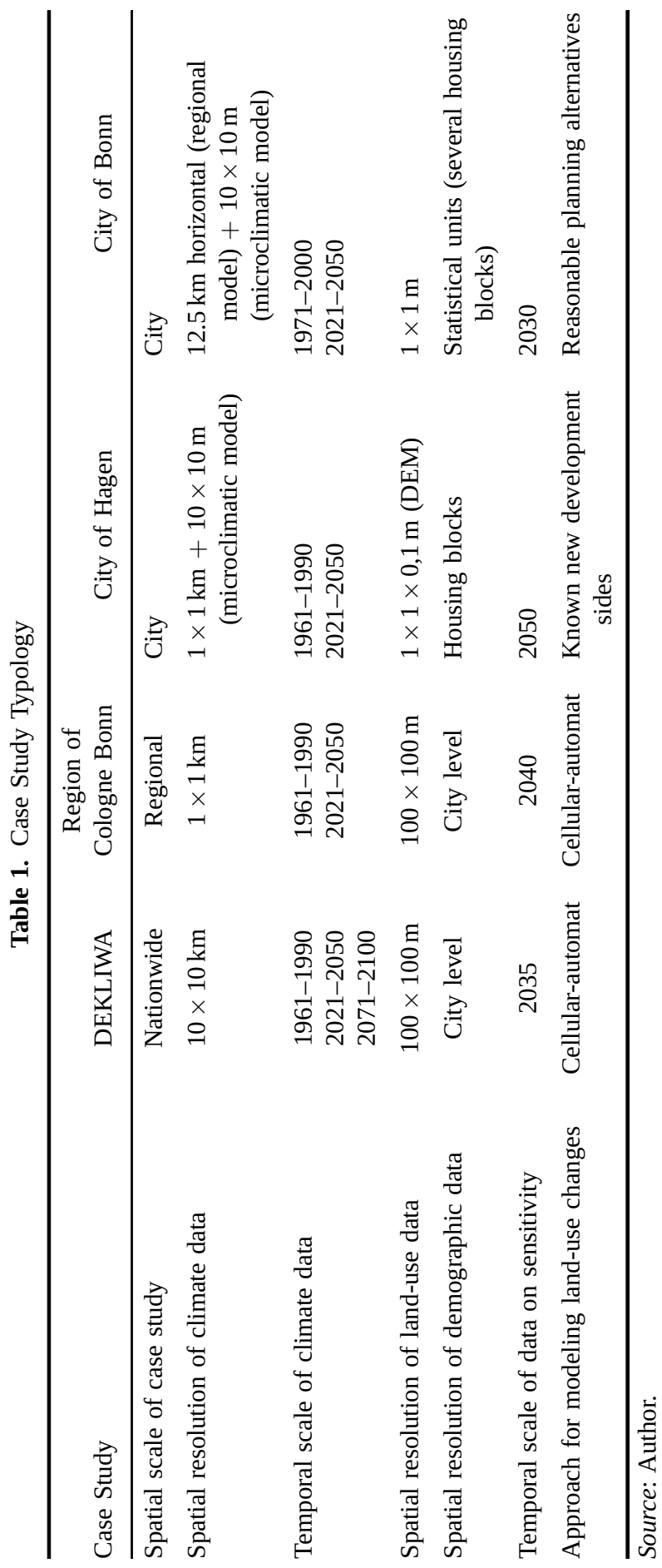




\subsection{Impact assessment on national scale}

The project DEKLIWA (influence of demographic change on the sensitivity of cities to climate change, (German title: Einfluss des demographischen Wandels auf die Empfindlichkeit von Städten gegenüber dem Klimawandel)), which is funded by the Deutsche Forschungsgemeinschaft (DFG), provides an analysis of the impacts that the main features of demographic change (e.g., aging, shrinkage, and heterogeneity of the population) have on the sensitivity of different types of urban structures with respect to climatic changes for Germany as a whole. The main focus of the project is the analysis of the influence of demographic change on the sensitivity of cities that are facing consequences of a changing climate. Within the project, an integrated methodology is utilized to estimate the impact of the two mega-trends climate change and demographic change.

One of the main objectives of the project is the identification of an assessable combination of these megatrends in the near future (until 2035). For this purpose, a nationwide spatial analysis was conducted. This analysis of both demographic and climate changes had two main targets. The first target was to find representative case studies for each combination of climate and demographic change. The second target aimed at the identification of spatial patterns regarding both megatrends.

To achieve these targets, the analysis of climate and demographic change followed the parallel modeling approach. The assessment was done on basis of the typology of climate change regions, generated by the "Netzwerk Vulnerabilität”, a network of researchers and German Federal Agencies and Institutions that carried out a national climate change vulnerability assessment (adelphi/PRC/EURAC 2015). The typology of climate change regions typecasts more than eleven climate signals into six homogenous regions of climate change in Germany for the timescales presence $(t 0)$, near future $(t 1)$ and remote future $(t 2)$ (adelphi/PRC/EURAC 2015). Regarding sensitivity, data from the demographic types of the Bertelsmann Stiftung were used. These demographic types typecast all German cities with more than 5,000 inhabitants into nine homogenous types with similar demographic trends, like "prosperous communities near dynamic economic centers" or "rapidly shrinking communities under great pressure to adapt". Basis for this classification is a set of 220 indicators which have been collected and utilized for the 2,915 cities in Germany with more than 5,000 inhabitants (Website Bertelsmann-Stiftung 2018).

Within the nationwide analysis, both trends had been spatially intersected as shown in Figure 3.

The parallel modeling approach was used to figure out how many cities and inhabitants live in which climate type and how their specific socioeconomic characteristics are. For this, the presence typology of climate change regions was 
Climate Change and Extreme Events

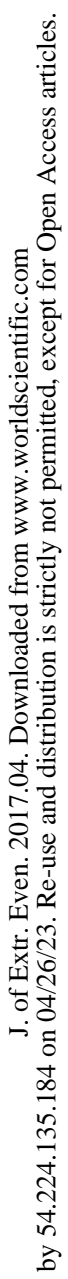

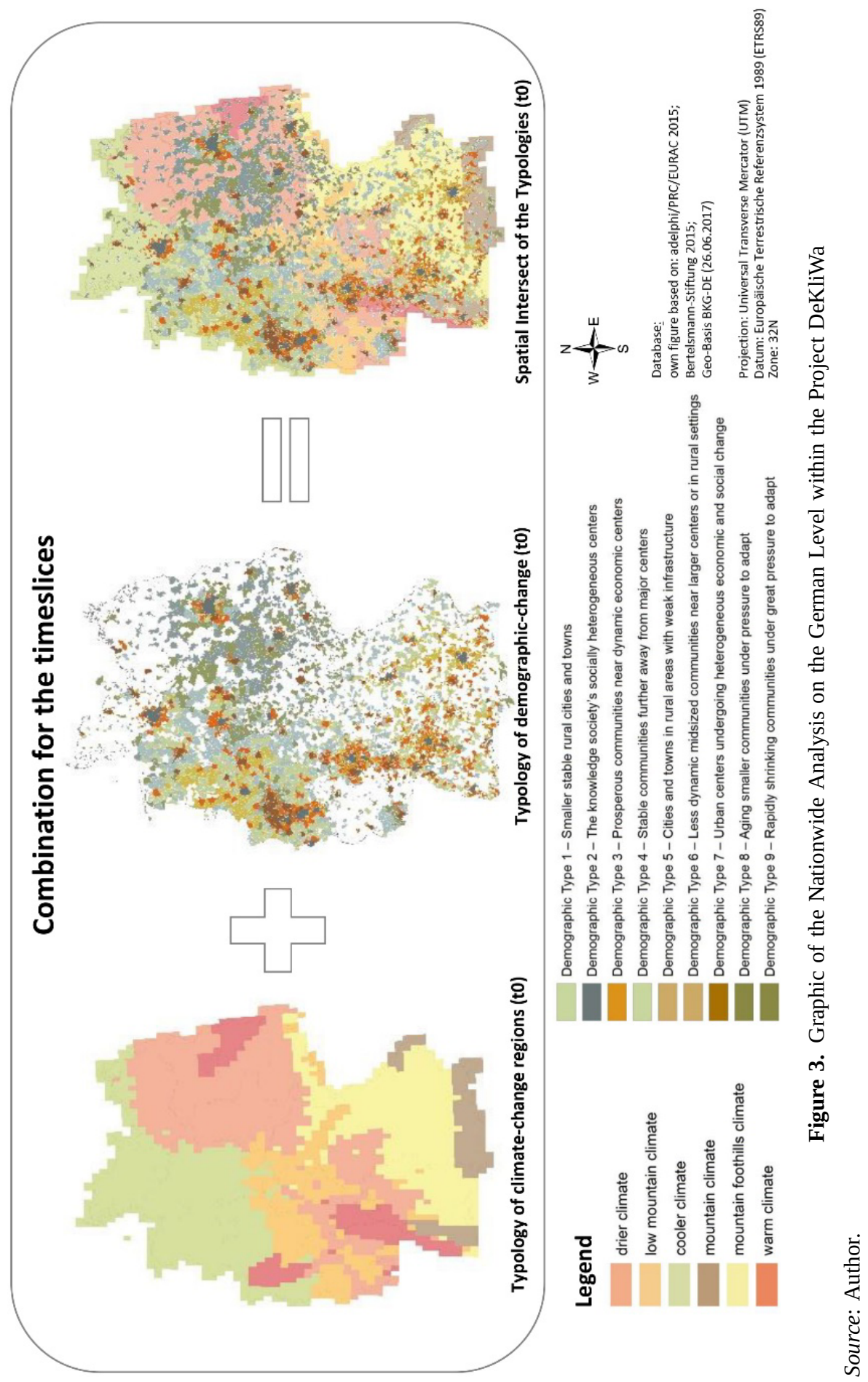


spatially intersected with the demographic types. Information regarding the amount of cities of each demographic type and the amount of inhabitants for each typology of climate change were analyzed, as well as other socioeconomic data like the median age, the amount of single-person households, and the purchase power. The same intersect was implemented with the climate types in the near future and the future amount of cities and inhabitants with their sociodemographic characteristics (Schulze-Dieckhoff et al. 2018).

By applying the parallel modeling approach on the nationwide level, some significant results have been revealed which show specific need for action especially for spatial planning. For example, cities with a growing population are more likely to be found in climatic types which will be exceptionally warmer than others. This phenomenon will lead to specific problems especially with regard to the guiding principle of compact cities, which is propagated by both, the Regional Planning Act (ROG) and the Federal Building Code (BauGB), in order to mitigate transportation effects and protect open spaces. The climate change region with a significant trend for droughts has a conflicting trend, too. In this climate change region, the majority of cities will have a decrease in inhabitants in the near future which will lead to further problems especially concerning the maintenance of municipal technical infrastructures such as the sewage system whose capacity is not fully used anymore, but at the same time not sufficiently adapted to storm water management. This leads to an enormous financial burden for the remaining users (Schulze-Dieckhoff et al. 2018).

The parallel modeling approach used within the analysis was also useful to identify the significance of demographic change with regard to climate change. It showed that due to the demographic change until the near future many sensitivity factors like the amount of people, specific cohorts and other adaptation relevant parameters will change significantly. This change in sensitivity induced by demographic change will lead to spatially different challenges with regard to the regionally varying impacts of climate change. The analysis underlines that a key factor to tailor-made adaptation is to take the change in sensitivity into account.

\subsection{Impact assessment on regional scale - the example of the region of Cologne Bonn}

Purpose of the project "Climate change adaptation strategy for the Region of Cologne/Bonn”, funded by the Region Köln/Bonn e. V., is the creation of a regional adaptation strategy to climate change. The first step was the conduction of an impact assessment in order to create an evidence basis for adaptation actions to be taken in accordance with a specific impact profile. The examined climatechange-related impacts are the effects of river floods and flash floods on residential 
areas and transport infrastructure and the impacts of heat and drought stress on agriculture and forestry. The conceptual core of the climate impact assessment is the parallel modeling approach. The objective of the assessment was to determine the specific climate impacts for all of the 60 municipalities (level of analysis for the larger cities Cologne and Bonn: city districts) within the Region of Cologne Bonn.

A particular challenge was the acquisition of sensitivity data for the future. Due to a lack of current and reliable land-use models or alternative information on the future settlement development laid down in a regional plan, it was necessary to generate reliable land-use data within the project. In principle, a regional plan is a good basis for modeling land use in Germany because it lays down the spatial structure for the future. This applies especially for North Rhine-Westphalia where general settlement areas (ASB - German title: Allgemeine Siedlungsbereiche) are designated within the regional plan. Only within these ASB, the municipalities are entitled to designate new settlement areas by means of local land-use plans. However, the regional plan for the Regierungsbezirk Köln (District of Cologne, including the largest part of the Region Cologne Bonn) came into force in 2006 and is currently under review. The ASB, which are demarked in this regional plan, are not reliable anymore. The new plan is on the way, but there was no approved draft available, which contains information on further land use.

Based on existing regional population projections, a differentiated demand for residential zones was calculated for each municipality or city district, respectively. On this basis, two different land-use scenarios were implemented to determine the bandwidth of possible settlement developments. In one scenario, a more endogenous settlement development was assumed; in the other, a more exogenous development with a higher land consumption. Moreover, the expansion of residential areas is less restrictive in the scenario "exogenous development" (e.g., it is allowed to build residential areas in current existing landscape protection areas whereas these areas were excluded in the scenario "endogenous development"). It is assumed in both scenarios that the development of residential land use is the more likely the lower the distance to existing settlements is. Figure 4 shows a map section with the result of the two assumed development scenarios for residential land-use south of Cologne. As shown, not all general settlement areas (ASB) from the regional plan are developed in any of the scenarios. This is due to the fact that in some municipalities or districts the demand is already saturated or the population is declining. Already existing residential areas are assumed as persistent in the future.

With knowledge of such future residential areas, it is possible to calculate future climate impacts more accurately. For example, the change in the flood-prone areas (considered as "climate influence") can be geographically intersected with future 


\section{Scenarios for the development of residential areas}

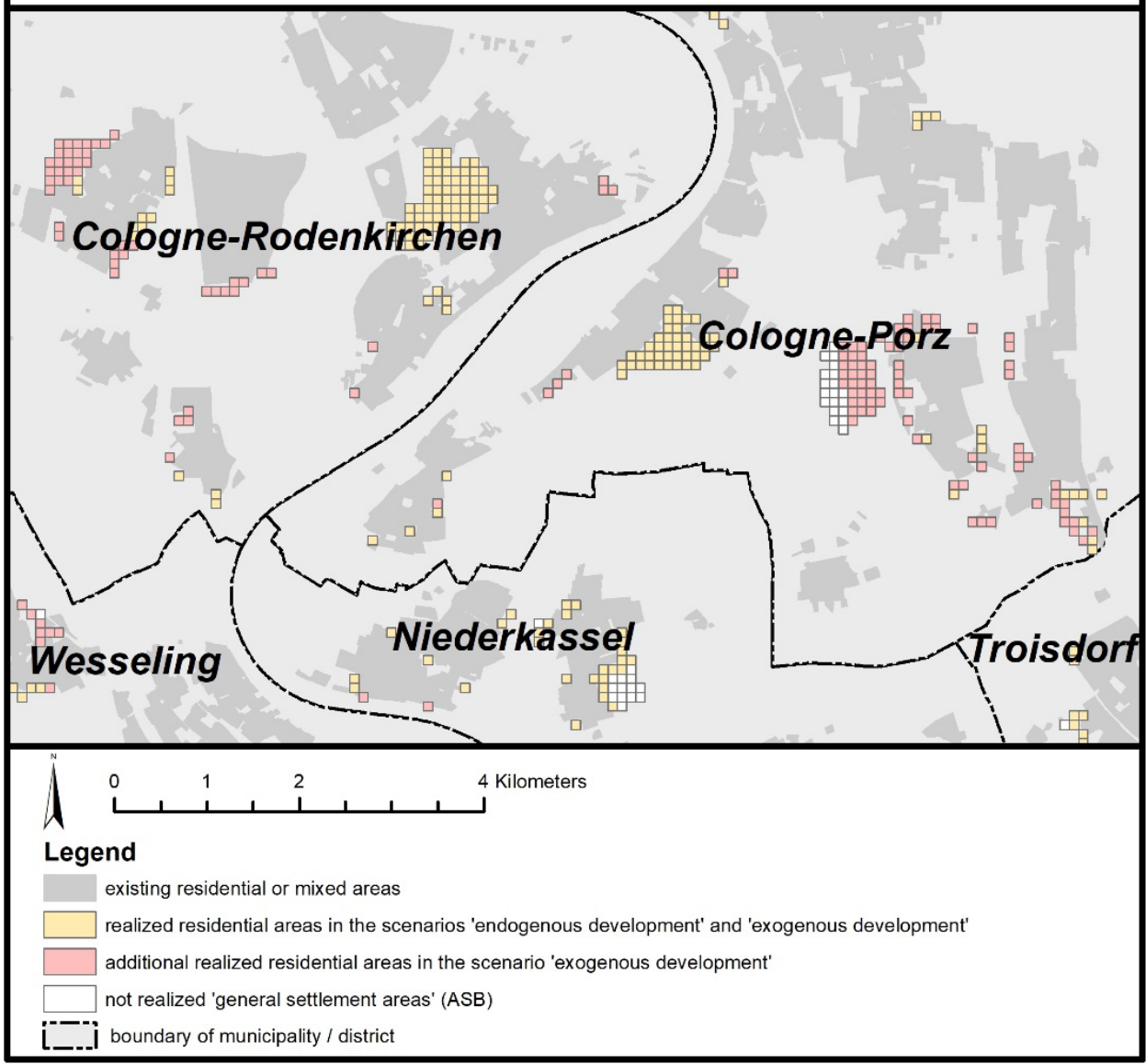

Figure 4. Alternative Scenarios for the Development of Residential Areas in the Region of Cologne Bonn

Source: Author.

residential areas ("sensitivity") to identify future flood impacts as well as changes compared with the current situation. Furthermore, the applied land-use model does not only show where residential areas are in the future, but also the decrease of other land-use types such as agricultural land. Consequently, it is possible to estimate future climate impacts relating to agricultural land use as well.

Depending on the specific purpose of the impact assessment, an appropriate spatial resolution of data for the future sensitivity is necessary. For example, in order to estimate flood impacts on population, it is not sufficient to use only data 
from population projections on a municipal level, because it is unclear where the population will settle within the municipality. The example of the region of Cologne Bonn shows that it is possible to estimate the location of future residential areas and corresponding impacts. The existence of general settlement areas (ASB) in the regional plans in North Rhine-Westphalia provides a reliable basis in this case. However, due to the existence of different spatial planning laws and instruments in other Federal States, the land-use model within the parallel modeling approach presented here cannot be similarly transferred to other regions of Germany or to other countries. Furthermore, the example of the region of Cologne Bonn shows the important role of spatial planning (in context of floods especially regional spatial planning) to minimize (or increase) flood impacts on residential areas. Due to the fact that general settlement areas (ASB) determine a specific land use, it becomes to a certain degree possible to identify future flood impacts. This approach follows the so-called "precautionary principle" and can be based on the results of the presented parallel modeling approach.

\subsection{Impact assessment on local scale for shrinking cities - the example of the City of Hagen}

The project Integrated adaptation concept for the City of Hagen (InKlaH), funded by the Federal Ministry for the Environment, Natural Conservation, Building and Nuclear Safety, aims at an integrated adaptation strategy to climate change and demographic change for the City of Hagen which is located in the federal state of North Rhine-Westphalia. It is intended to mainstream adaptation by coordinating actions like mitigation of urban heat and flood risk management strategies with land-use and landscape planning of the City of Hagen. This strategy is informed by an impact assessment that follows the parallel modeling approach.

The City of Hagen is characterized by a massive demographic change. The current population of Hagen (about 190,000 inhabitants) is ageing, increasingly heterogenic and significantly decreasing in its number. Extreme events and climatic stresses, like heat waves, flash floods and river flooding are a great burden for Hagen's ageing urban society. Simultaneously, these trends can to be seen as a window of opportunity for a retreat from hazard-prone areas because many primarily former industrial areas are not used anymore and are brownfields nowadays.

For the climate impact analysis, the climate stimuli heat stress, flash floods and river floods were analyzed for the presence and the near future in two-time frames (2015 and 2050). Hagen has a high risk of flash floods and river floods due to its hilly topography and numerous creeks and rivers. The urban settlements are located mainly in the river valleys, which leads at the same time to a significant 
heat island effect during day and night. Hence, the inhabitants of the city are and will even be more seriously affected by various climate impacts such as urban heat (see Figure 5).

For the analysis of urban heat, a holistic approach was applied in order to estimate the impact on human health from both climatic and demographic changes. For projecting the influence of climate change on the urban climate, the change in the number of heat days (more than $30^{\circ} \mathrm{C}$ ) and tropical nights (more than $20^{\circ} \mathrm{C}$ ) was projected. In this context, known potential changes in the settlements structure (depicted from political debates) were taken into account for calculating the future urban climate by means of the urban climate model ENVIMET (Bruse and Fleer 1998). Basis of the sensitivity analysis was the number and the change in the number of people in the age groups younger than 6 and older than 65 years. Additionally, the working population was considered since especially the daytime heat island effect will most likely increase in the future and may lead, e.g., to a lower productivity (Greiving et al. 2016).

Figure 5 shows the change of the impact of urban heat on human health. It is based on a composite index that merges heat days/tropical nights (equally weighted) with the number and density of the population per city quarter (age groups were differently weighted in accordance with their sensitivity to heat stress). The heat-related impact was calculated for the presence and the future. The

Heat Impact today and in the future in the City of Hagen

2015

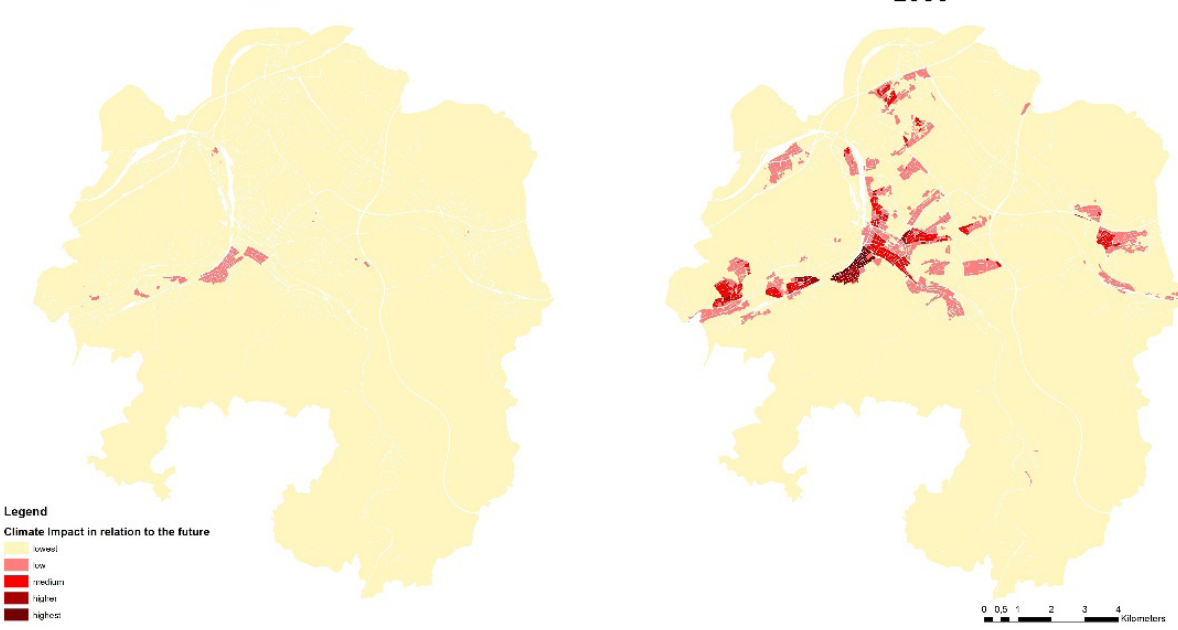

Figure 5. Temporal Change of the Heat Island Effect in the City of Hagen

Source: Author. 
values were normalized ( $0-1)$ over both time slices in order to visualize the change of the impact over time. It becomes clear, that tomorrow's impact on human health in suburban residential areas will be more serious than it is today in the densely populated city center.

The aim of this detailed analysis of the population composition was to find impact hotspots and their change over time. Due to a declining population, there are city districts with lower sensitivity in the future in comparison to others. However, the change in the heat stress (due to global warming and further settlement development) dominates the impact quantitatively in comparison to their demographic change. The consideration of demographic changes enables urban planning to implement tailor-made adaptation actions in accordance with a given demographic structure. It offers the opportunity to prioritize hotspots for the necessity of climate adaptation measures in order to ensure good living standards for the elderly or to improve disadvantaged city districts which lack, for instance, urban green.

The knowledge of climate impacts integrating demographic development offers a big potential to succeed in sustainable urban planning. The City of Hagen is confronted with enormous challenges due to its decreasing population and potential impacts of climate change. The parallel modeling approach offers an integrated view for planning decisions. The analysis widens the perspective by identifying potential future scenarios in terms of reasonable planning alternatives. However, the results are not representative for rapidly growing smaller- to medium-sized cities which are continuously expanding their urbanized areas and thus their risk to urban heat and extreme events (Birkmann et al. 2016).

\subsection{Impact assessment on local scale for growing cities - the example of the City of Bonn}

Consequently, another example for the application of the parallel modeling approach on local scale is presented here in order to discuss the suitability of the parallel modeling approach under growth: The analyses of heat-related climate change impacts within the ZURES project (Scenario-based vulnerability and risk analysis as a tool for promoting the resilience of cities and critical infrastructures) which is funded by the German Federal Ministry of Education and Research (BMBF - German title: Bundesministerium für Bildung und Forschung). The project aims at the development of new methods and instruments for a futureoriented vulnerability and risk assessment of urban areas - taking into account heat stress and social transformation processes. In close cooperation with the cities of Bonn and Ludwigsburg, past transformation processes are identified and future 
changes and scenarios of the climate and in parallel of the settlement and socioeconomic structure (especially sensitive urban groups) are estimated. In contrast to the City of Hagen, the situation in the cities of Bonn and Ludwigsburg is different: both cities have been developing dynamically in the last decades and the future projections show a large increase in population, housing demand and growing pressure on open space and natural areas, respectively.

One of the innovative elements of the project is that the vulnerability assessment is done for two different time scales. This is addressed by a set of scenarios of changes in the urban structure (land consumption, increase of density) as well as for the population's sensitivity. In a first step, two scenarios were developed in order to describe the scope of possible future changes of the urban structure. The approach is described in the following by the example of the City of Bonn which has - despite of losing its function of being the capital and the seat of the German federal government to Berlin - experienced a strong population increase from about 290,000 in 1990 to almost 325,000 in 2017 (Stadt Bonn 2017). Some projections estimate a population of 362,000 by the year 2030 (IT.NRW 2012).

In order to allow for considering this dynamic development in the analysis of the future urban climate, two scenarios were discussed and agreed in a collaborative scenario workshop between the research team of the ZURES project and representatives from the city administration of Bonn (e.g., from offices for the environment, planning and business development). Starting point was the projected future population in the year 2030 and the additional 20,000 housing units that are needed to satisfy the demand. The two scenarios as reasonable planning alternatives differ from each other by the way how the additional housing units will be allocated within the City of Bonn. The balanced scenario describes a development where a moderate number of housing units will be built within the already built-up areas whereas the larger number will be built in the surrounding open space, e.g., due to an increased city-regional co-operation. The densified scenario is characterized by the allocation of all additional housing units within the built-up areas ("in-fill" strategy, guided by the planning principle of a compact city) (Table 2).

The analysis of the urban climate will then be carried out for the present situation (recent climate situation and today's urban structure) as well as for a future situation with moderate changes (balanced urban scenario with moderate climate change) and strong changes (densified urban scenario with strong climate change). The results of this parallel modeling approach will then show the scope of the future urban heat island effects under various conditions.

The results of the urban climate analysis (based on the urban climate model FITNAH, see GEONET 2018) will be streamlined with a set of different socioeconomic scenarios (business as usual, forecasting, backcasting) which are 
Table 2. Comparison of the Two Urban Structure Scenarios for the City of Bonn

\begin{tabular}{lcc}
\hline \multicolumn{3}{c}{ Starting Point } \\
\hline Population (2015/2030) & \multicolumn{2}{c}{$320,800 / 362,000$} \\
Additional housing units needed & \multicolumn{2}{c}{-20,000 } \\
Allocation of additional housing units & "balanced scenario" & "densified scenario" \\
In existing potential housing areas & 6,200 & 6,200 \\
In empty sites & 1,500 & 1,500 \\
In future potential housing areas & 0 & $5,000^{*}$ \\
By vertical extension of multi-storey flats & 0 & $7,300^{*}$ \\
$\quad$ of the 1950s to 1970s by 2 storeys & 12,300 & 0 \\
Outside the City of Bonn & & \\
\hline
\end{tabular}

Source: Author.

*Estimation based on the difference between the existing potential and the needed housing units.

described qualitatively and for some core indicators even quantitatively (sensitivity-related aspects such as age, income, population density, accessibility to open spaces and green areas). Thus, the parallel modeling approach also covers aspects of social sensitivity. The results of the analyses are coupled with formal and informal instruments and assessment methods of urban development, in order to strengthen institutional planning tools for future-oriented transformation management. On this evidence basis, a political decision about the further urban development strategy has to be taken.

\section{Discussion}

The results from the different applications proved the hypothesis, that the change in sensitivity (i.e., demographic change, economic change and change in land-use patterns) often determines the magnitude of climate- and weather-related impacts in the near future significantly. Which factor (change of the climate or change of the sensitivity) matters more cannot be generalized, but depends on the dynamics of local effects of climate change on the one hand and demographic changes and related change of the land use on the other hand? Generally speaking, sensitivityrelated factors are more relevant, the more dynamic the land-use changes are. This is particularly troublesome for growing economies in the Global South whose landuse changes are heavily influenced by informal settlement developments that are often out of the control of land-use planning (Greiving et al. 2016).

The identified relevance of changes in the sensitivity in context of the presented case studies are plausible in view of the fact that severe climatic changes are likely to occur only after the 2050s, while the sensitivity of the socioeconomic system will most likely undergo rapid changes already in the coming decades (IPCC 2014). 
Monitoring and evaluating climate change adaptation policies is essential at each spatial level in order to assess their effectiveness, but also potential side effects on other policy fields. These tasks should be mainstreamed into existing monitoring programs such as those established by the EIA and strategic environmental assessment (SEA) directives (monitoring of unforeseen effects on the environment) and other framework directives (e.g., the Floods Directive) (EC 2014; EEA 2015).

Moreover, the given deep uncertainty of the future status of both climate and society calls for flexible, resilient adaptation strategies (Walker et al. 2013). Here, the "no-regret" principle comes into play: strategies that foster a more balanced development promise a net benefit irrespectively of the extent of future impacts of climate change which cannot be precisely predicted (Hallegatte 2009). Such multifunctionally justifiable solutions are more acceptable for the affected population than stand-alone adaptation measures. A good example can be found in urban greening concepts that are effective in terms of mitigating urban heat in densely populated city centers and can also be used for storing storm water in order to unburden sewage systems. At the same time, these concepts enhance the living quality in a city quarter (Webb 2017).

\section{Conclusions}

The four case studies represent different methodological approaches for both modeling the climatic and socioeconomic changes. Only a parallel modeling of both components enables planning authorities and decision-makers to ground adaptation actions on a sound evidence basis.

However, the different spatial scales require adjusted methods for modeling socioeconomic changes. On the national and regional levels, land-use models informed by demographic projections, are the appropriate way to assess a changing sensitivity due to a lack of detailed knowledge of potential local land-use changes. On the local level, this local knowledge such as fine-grained demographic data including information on age groups, social milieus and ethnics is available and allows a more precise assessment of the sensitivity. Moreover, based on reasonable alternatives of further settlement expansion or urban renewal, reliable scenarios for local land-use change can be created. These scenarios enable an iterative process between urban climatic modelers and urban developers. In doing so, planning alternatives that are optimized to the potential future status of the climate, can be derived. That is exactly what the Strategic Environmental Assessment Directive 2001/42/EC) requires when asking for these "reasonable alternatives” (Art. 5 §1), 
but what is rarely done in planning practice. Thus, the presented approach contributes to an enhancement of the quality of Strategic Environmental Assessments.

Mostly, the current status of the system was compared with the status in the near future. In this context, the temporal scale of data for sensitivity slightly differs (from 2030 in Bonn, 2035 in DEKLIWA, 2040 in Cologne Bonn to 2050 in Hagen) due to the specifics of the available data sets. Generally speaking, the quality of assessment depends - apart from the chosen methods - on the quality of the input data. An enormous challenge in this regard is the lack of available and reliable demographic data - and subsequently land-use data - for the remote future. There is definitely a need for future research in this respect. Only the nationwide study considered the remote future, but only in regard to climatic data. Another limiting factor is the deep uncertainty concerning the future potential change of the local patterns of extreme events such as urban flooding. Here, the available data from regional climatic models is not sufficient as it offers for instance just the 98th percentile data for daily rainfall which does not represent real extreme events.

Consequently, normative decisions are needed for determining the framework conditions for scenarios and selecting reasonable alternatives. These kinds of decisions were taken in close collaboration with the addressees of the assessments in all case studies: in the DEKLIWA project the selection of scenario combinations (15th and 85th percentile), in Cologne Bonn the restrictions for further settlement development as an input variable for the cellular automat, in Hagen the change of the 1:100-year rainfall intensity and in Bonn the reasonable planning alternatives. Thus, all presented applications proved the introductory statement that adaptation needs to be organized in a collaborative way which takes the knowledge, but also the concerns of the addressees into full account - from the early beginning of the problem framing and the impact assessment to the selection of adaptation measures.

\section{References}

Birkmann, J and Mechler R (2015). Advancing climate adaptation and risk management. New insights, concepts and approaches: What have we learned from the SREX and the AR5 processes? Climatic Change, 133(1): 1-6, doi: 10.1007/s10584-015-1515-y. Birkmann, J, Welle T, Solecki W, Lwasa S and Garschhagen M (2016). Boost resilience of small and mid-sized cities - Smaller settlements are growing faster than megacities — and they need more protection from extreme events. Nature, 537: 605-608.

Bruse, $M$ and Fleer H (1998). Simulating surface-plant-air interactions inside urban environments with a three dimensional numerical model. Environmental Modelling and Software, 13: 373-384. 
Costa, L and Kropp J (2012). Linking components of vulnerability in theoretic frameworks and case studies. Sustainable Sciences, 8(1): 1-9.

EC (2001). Directive 2001/42/EC of the European Parliament and of the Council of 27 June 2001 on the assessment of the effects of certain plans and programmes on the environment. http://eur-lex.europa.eu/legal-content/EN/TXT/PDF/?uri=CELEX:32001L0042\&from=EN [March 28, 2018].

EC (2013). Commission Staff Working Document "Guidelines on Developing Adaptation Strategies”. SWD 2013134 final. Brussels. https:/ec.europa.eu/clima/sites/clima/ files/adaptation/what/docs/swd_2013_134_en.pdf [March 28, 2018].

EC (2014). Investment for Jobs and Growth - Promoting Development and Good Governance in EU Regions and Cities. Sixth Report on Economic, Social and Territorial Cohesion. Luxembourg: Publications Office of the European Union.

EC DG Environment (2013). Guidance on Integrating Climate Change and Biodiversity into Strategic Environmental Assessment. European Union, Brussels. http://ec.europa.eu/environment/eia/pdf/SEA\%20Guidance.pdf [October 7, 2015].

EEA (2012). Climate Change, Impacts and Vulnerability in Europe 2012. An IndicatorBased Report. EEA.

EEA (2013). Adaptation in Europe - Addressing Risks and Opportunities from Climate Change in the Context of Socio-economic Developments. EEA Report No. 3/2013. Copenhagen, Denmark: European Environment Agency.

EEA (2014). National Adaptation Policy Processes in European Countries. EEA Report No. 4/2014. Copenhagen, Denmark: European Environment Agency.

EEA (2015). National Monitoring, Reporting and Evaluation of Climate Change Adaptation in Europe. EEA Report No 20/2015. Copenhagen, Denmark: European Environment Agency.

EEA (2016). Flood Risks and Environmental Vulnerability - Exploring the Synergies between Floodplain Restoration, Water Policies and Thematic Policies. EEA Report No. 1/2016. Copenhagen, Denmark: European Environment Agency.

EEA (2017). Climate Change, Impacts and Vulnerability in Europe 2016. EEA Report No. 1/2017, https://www.eea.europa.eu/publications/climate-change-impacts-and-vulnerability-2016.

Field, CB, Barros V, Stocker TF, Qin D, Dokken DJ, Ebi KL, Mastrandrea MD, Mach KJ, Plattner G-K, Allen SK, Tignor M, and Midgley PM (2012). Managing the Risks of Extreme Events and Disasters to Advance Climate Change Adaptation, A Special Report of Working Groups I and II of the Intergovernmental Panel on Climate Change. Cambridge, UK and New York, NY, USA: Cambridge University Press.

Fleischhauer, M, Greiving S, Flex F, Scheibel M, Stickler T, Sereinig N, Koboltschnig G, Malvati P, Vitale V, Grifoni P and Firus K. (2012). Improving the active involvement of stakeholders and the public in flood risk management - tools of an involvement strategy and case study results from Austria, Germany and Italy. Natural Hazards and Earth System Science, 12: 2785-2798.

GEONET (2018). Wind Field Simulation with 3D Flow Model FITNAH, http://www.geonet.de/fileadmin/user_upload/pdf/Wind/FITNAH.pdf [January 3, 2018]. 
Greiving, S and Fleischhauer M (2012). National climate change adaptation strategies of European states from a spatial planning and development perspective. European Planning Studies, 20(1): 27-47.

Greiving, S, Schmidt-Thomé P, Davoudi S, Peltonen L and Sprague T (2013). Implications for territorial development and challenges for the territorial cohesion of the European Union. In: Schmidt-Thomé, P and Greiving S (eds.), European Climate Vulnerabilities and Adaptation: A Spatial Planning Rerspective. London: Wiley \& Blackwell, pp. 295-322.

Greiving, S, Tesliar J and Ubaura M (eds.) (2016). Spatial Planning and Resilience Following Disasters - International and Comparative Perspectives. Bristol: Policy Press, 354 pp.

Greiving, S, Zebisch M, Schneiderbauer S, Lindner C, Lückenkötter J, Fleischhauer M, Buth M, Kahlenborn, W and Schauser I (2015). A consensus based vulnerability assessment to climate change in Germany. International Journal of Climate Change Strategies and Management, 7(3): 306-326.

Hallegatte S (2009). Strategies to adapt to an uncertain climate change. Global Environmental Change, 19: 240-247.

IPCC (2014). Climate Change 2014: Synthesis Report. In: Pachauri, RK and Meyer LA (eds.), Contribution of Working Groups I, II and III to the Fifth Assessment Report of the Intergovernmental Panel on Climate Change. Geneva, Switzerland: IPCC.

IT.NRW (2012). Bevölkerungsvorausberechnung, http://www.it.nrw.de/presse/pressemitteilungen/2012/pdf/112_12.pdf [January 18 2018].

Kern, K and Bulkeley H (2009). Cities, Europeanization and multi-level governance: Governing climate change through transnational municipal networks. Journal of Common Market Studies, 47: 309-332.

Knieling, J and Filho WL (2013). Climate Change Governance - Climate Change Management. Berlin Heidelberg: Springer Verlag.

Mickwitz, P, Aix F, Beck S, Carss D, Ferrand N, Görg C, Jensen A, Kivimaa P, Kuhlicke C, Kuindersma W, Manez M, Melanen M, Monni S, Pedersen AB, Reinert H and Van Bommel S (2009). Climate Policy Integration, Coherence and Governance. PEER Report No. 2, Helsinki. http://files.ifok.de/all/klima/IFOK-Studie_Klimaanpassung.pdf [January 19, 2011].

Reckien, D, Flacke J, Dawson RJ, Heidrich O, Olazabal M, Foley A, Hamann JJ-P, Orru H, Salvia M, de Gregorio Hurtado S, Geneletti D and Pietrapertosa F (2014). Climate change response in Europe: What's the reality? Analysis of adaptation and mitigation plans from 200 urban areas in 11 countries. Climatic Change, 122(1-2): 331-340.

Rojas, R, Feyen L, Bianchi A and Dosio A (2012). Assessment of future flood hazard in Europe using a large ensemble of bias corrected regional climate simulations'. Journal of Geophysical Research, 117: D17109, doi: 10.1029/2012JD017461.

Schulze-Dieckhoff, V, Becker D, Wiechmann T and Greiving S (2018). Spatial patterns: Demographic change and climate change in German cities. Journal of Spatial Research and Planning. Accepted Paper (December 21, 2017): In print.

Stadt Bonn (2017). Bonn in Zahlen. http://www.bonn.de/rat_verwaltung_buergerdienste/ aktuelles/bonn_in_zahlen/index.html [January 18, 2018]. 
UN-ISDR (2015). Sendai Framework for Disaster Risk Reduction 2015-2030, The United Nations Office for Disaster Risk Reduction. Geneva. Switzerland. https://www.preventionweb.net/files/43291_sendaiframeworkfordrren.pdf [March 28, 2018].

van Asselt, M (2005). The complex significance of uncertainty in a risk era: Logics, manners and strategies in use. Risk Assessment and Management, 5(2/3/4): 125-158.

van Ruijven, BJ, Levy MA, Agrawal A, Biermann F, Birkmann J and Carter TR (2014). Enhancing the relevance of Shared Socioeconomic Pathways for climate change impacts, adaptation and vulnerability research. Climatic Change, 122(3): 481-494.

van Vuuren, DP, Edmonds J, Kainuma M, Riahi K, Thomson A, Hibbard K, Hurtt GC, Kram T, Krey V, Lamarque JF, Masui T, Meinshausen M, Nakicenovic N, Smith SJ and Rose SK (2011). The representative concentration pathways: An overview. Climatic Change, 109(5), doi: 10.1007/s10584-011-0148-z.

Walker, WE, Haasnoot M and Kwakkel JH (2013). Adapt or perish: A review of planning approaches for adaptation under deep uncertainty. Sustainability, 5: 955-979.

Walker, G, Tweed F and Whittle R (2014). A framework for profiling the characteristics of risk governance in natural hazard contexts. Natural Hazards and Earth System Sciences, 14(1): 155-164.

Webb, B (2017). The use of urban climatology in local climate change strategies: A comparative perspective. International Planning Studies, 22(2): 68-84, doi: 10.1080/13563475.2016.1169916.

Website Bertelsmann-Stiftung (2018). https://www.bertelsmann-stiftung.de/en/our-projects/communities-shaping-demographic-change/project-topics/communities-demographic-types/ [January 4 2018]. 